\title{
Resveratrol promotes the sensitivity of small-cell lung cancer H446 cells to cisplatin by regulating intrinsic apoptosis
}

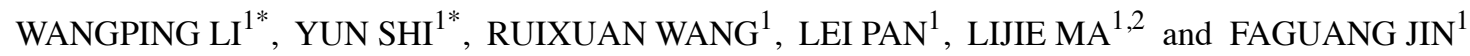 \\ ${ }^{1}$ Department of Respiration, Tangdu Hospital, Fourth Military Medical University, Xi'an, Shaanxi 710038; \\ ${ }^{2}$ Department of Respiration, Chengdu Military General Hospital, Chengdu, Sichuan 610083, P.R. China
}

Received September 20, 2017; Accepted July 10, 2018

DOI: 10.3892/ijo.2018.4533

\begin{abstract}
The aim of the present study was to evaluate the effects of resveratrol on small-cell lung cancer (SCLC) cell proliferation and apoptosis. The results demonstrated that resveratrol concentration- and time-dependently reduced $\mathrm{H} 446$ cell viability. In addition, cells treated with resveratrol displayed higher apoptotic rates, in association with mitochondrial depolarization, cytochrome $c$ release from the mitochondrial compartment to the cytoplasm, apoptosis-inducing factor translocation from the mitochondrial compartment to the nucleus, and altered protein levels of Bcl-2, Bcl-xL and Bax. Furthermore, resveratrol promoted H446 cell inhibition by cisplatin, as reflected by reduced viability and increased apoptosis. These findings suggest that resveratrol exerts antitumor effects on SCLC H446 cells and promotes H446 cell killing by cisplatin via modulation of intrinsic apoptosis.
\end{abstract}

\section{Introduction}

Lung cancer, a very common type of cancer, has become the leading cause of cancer-related mortality worldwide (1). Approximately $15-20 \%$ of all lung carcinomas are categorized as small-cell lung cancer (SCLC), which is of neuroendocrine origin and is characterized by aggressiveness and high metastatic potential (2). Strikingly, $>2 / 3$ of SCLC cases are detected as advanced cancer with associated metastasis, with a 5-year survival rate as low as 5-10\% (3). Cisplatin-based chemotherapy is the most commonly applied treatment for

Correspondence to: Dr Faguang Jin, Department of Respiration, Tangdu Hospital, Fourth Military Medical University, 169 Changle West Road, Xi'an, Shaanxi 710032, P.R China

E-mail: jinfag@fmmu.edu.cn

Dr Lijie Ma, Department of Respiration, Chengdu Military General Hospital, 270 Tianhui Road, Rongdu Avenue, Jinniu, Chengdu, Sichuan 610083, P.R. China

E-mail: mljp321@163.com

*Contributed equally

Key words: small-cell lung cancer, resveratrol, cisplatin, mitochondrial pathway, cell apoptosis
SCLC patients; however, it is not as effective as originally reported, due to the development of drug resistance. Therefore, methods that can enhance the effects of cisplatin and/or relieve pain in SCLC patients are urgently needed.

Resveratrol (Res; 3,4',5-trihydroxystilbene; C14H12O3) widely exists in grapes, berries, peanuts and wine, and possesses multiple confirmed therapeutic properties such as antioxidant, anti-inflammatory, anti-apoptotic and anticancer properties (4-9). Indeed, Res suppresses malignant cell growth and reduces the expression levels of cancer-related genes; in addition, it induces cell cycle arrest and apoptosis (10-13). More importantly, accumulating evidence suggests that Res promotes cancer cell apoptosis via Bcl-2 downregulation, Bax upregulation and activation of various caspases (13-16). Furthermore, Res alters mitochondrial function, redox state and mitochondrial synthesis (17). Previous studies have assessed the pharmacological effects of Res on NSCLC (18). However, only few studies have focused on its effects on SCLC.

Based on this evidence, it was hypothesized that Res stimulation may promote apoptosis of SCLC H446 cells by inducing mitochondrial dysfunction and regulating apoptotic factors. Therefore, the aim of the present study was to assess the pro-apoptotic effects of Res on H446 cells and investigate whether it promotes the inhibitory effects of cisplatin on SCLC cells and the underlying mechanism.

\section{Materials and methods}

Cell culture. SCLC H446 cells were provided by the American Type Culture Collection (Manassas, VA, USA) and maintained in RPMI-1640 containing 10\% fetal bovine serum (Gibco; Thermo Fisher Scientific, Waltham, MA, USA) in a humidified environment with $5 \% \mathrm{CO}_{2}$ at $37^{\circ} \mathrm{C}$.

Growth inhibition assay. H446 cells in the logarithmic growth phase were seeded in 96-well plates and treated with Res at various concentrations for $24 \mathrm{~h}(\mathrm{n}=8)$. The optimal Res concentration was further assessed at 12, 24 or $48 \mathrm{~h}(\mathrm{n}=8)$. In addition, H446 cells were treated with Res and cisplatin simultaneously. After treatment, MTT (5 mg/ml, $15 \mu \mathrm{l} /$ well) was added to each well and incubated for another $4 \mathrm{~h}$. Then, the supernatant was replaced by $200 \mu 1 \mathrm{DMSO}$ and absorbance was read at $492 \mathrm{~nm}$ on a Bio-Rad 550 microplate reader (Bio-Rad Laboratories, Shanghai, China). 


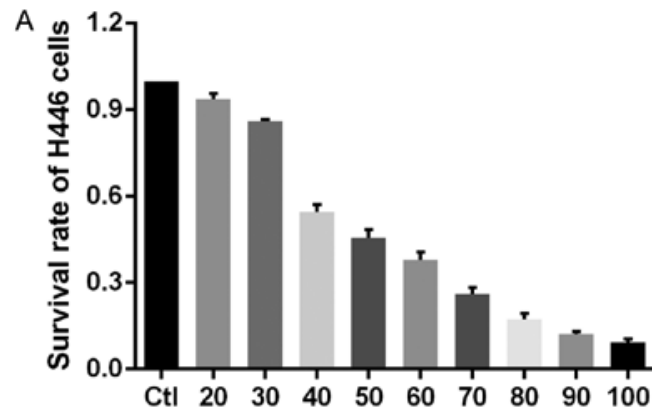

C

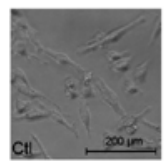

Resveratrol: $\mu \mathrm{g} / \mathrm{ml}$

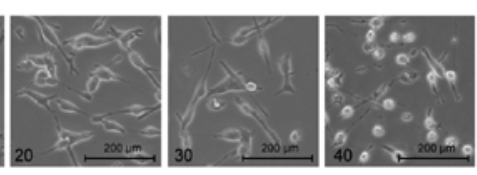

Resveratrol: $\mu \mathrm{g} / \mathrm{ml}$

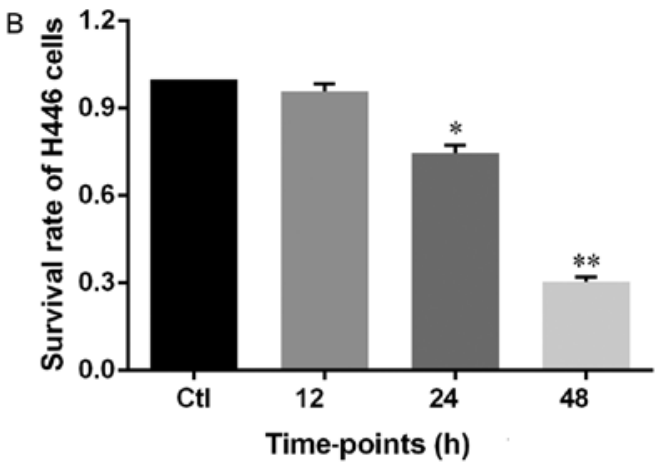

D

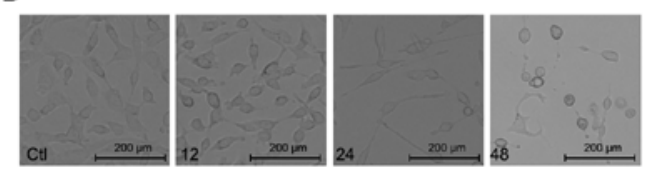

Time-points (h)

Figure 1. Resveratrol (Res) inhibits H446 cell proliferation as assessed by the MTT assay. Resveratrol reduced H446 cell proliferation in a (A) concentrationand (B) time-dependent manner. ${ }^{*} \mathrm{P}<0.05$ vs. control group; ${ }^{* *} \mathrm{P}<0.05$ vs. ${ }^{*} \mathrm{P}$. (C and D) Microscopic changes in $\mathrm{H} 446$ cells treated with $0,20,30$ and $40 \mu \mathrm{g} / \mathrm{ml}$ of Res for $24 \mathrm{~h}$, or $35 \mu \mathrm{g} / \mathrm{ml}$ for 12,24 and $48 \mathrm{~h}$.

Assessment of morphological alterations in cells. H446 cells were cultured in 24-well plates and treated as described above. Then, morphological changes in the cells were observed under a microscope (DMI6000B, Leica Microsystems GmbH, Wetzlar, Germany) at a magnification of x100. The effects of Res, cisplatin and Res/cisplatin combination on H446 cells were reflected by the morphological changes.

Flow-cytometric analysis of cellular apoptosis. Cellular apoptosis was measured using flow cytometry. In brief, H446 cells were collected after treatment with Res, cisplatin, or Res/cisplatin combination, and incubated with PI and Annexin V-FITC solution (BD Biosciences, Franklin Lakes, NJ, USA), according to the manufacturer's instructions. Analysis was performed on a flow cytometer (BD Biosciences).

Measurement of intracellular reactive oxygen species (ROS) levels. In order to assess ROS level changes in cells treated with Res, cisplatin, or Res/cisplatin combination, H446 cells from each group were stained with 2',7'-dichlorodihydrofluorescein diacetate (DCF-DA) and assessed with flow cytometry. The mean fluorescence intensity of DCF was considered to reflect the intracellular ROS level.

Mitochondrial membrane potential (MMP) assessment. In order to assess MMP alterations after treatment with different Res concentrations, H446 cells were stained with tetrachlorotetraethylbenzimidazol carbocyanine iodide (JC-10; Beyotime Institute of Biotechnology, Shanghai, China) for $45 \mathrm{~min}$, and analyzed with a flow cytometer (BD Biosciences).

Western blotting. The cellular expression levels of the proteins of interest were measured by western blot analysis. Briefly, cytoplasmic, nuclear and total protein samples were extracted with specific protein extraction kits (BestBio Institute of Biotechnology, Wuhan, China). Total protein amounts in various fractions were quantified by the BCA assay with a commercially available kit (Keygen Institute of Biotechnology, Nanjing, China). Equal amounts of denatured protein $(20 \mu \mathrm{g})$ were resolved by $12 \%$ SDS-PAGE and transferred onto PVDF membranes (EMD Millipore, Billerica, MA, USA). After blocking with 5\% (w/v) non-fat milk, primary antibodies against apoptosis-inducign factor (AIF), Cyto-C, Bcl-2 and Bcl-xL (dilution, 1:2,000) were added for overnight incubation at $4^{\circ} \mathrm{C}$. The membranes were subsequently incubated with secondary antibodies at room temperature for $2 \mathrm{~h}$. Immunoreactive signals were revealed by the ECL detection system (ChemiScope 5300 Pro, CLiNX, Shanghai, China).

Statistical analysis. Experiments were repeated at least 3 times. Data are presented as mean \pm standard deviation (SD). The GraphPad Prism program (GraphPad Software, Inc., La Jolla, CA, USA) was used for statistical analyses. Treatment groups were compared by one-way analysis of variance followed by Dunnett's test, with $\mathrm{P}<0.05$ considered statistically significant.

\section{Results}

Res inhibits SCLC cells. As shown in Fig. 1, Res suppressed the proliferation of H446 cells and the IC50 of H446 cells was $\sim 35 \mu \mathrm{g} / \mathrm{ml}$ of Res. Cell proliferation suppression was observed in a concentration- (Fig. 1A) and time- (Fig. 1B) dependent manner, when assessed for $35 \mu \mathrm{g} / \mathrm{ml}$ at 12,24 and $48 \mathrm{~h}$, respectively. Therefore, Res at $35 \mu \mathrm{g} / \mathrm{ml}$ was used in subsequent experiments.

Treatment with Res leads to morphological changes in H446 cells. The morphological changes in H446 cells treated with Res were assessed. As shown in Fig. 1C and D, normal cells distributed throughout the microscopic field were found in the control group; the cell bodies were stretched into various directions, and the nucleus remained in the center of each cell surrounded by a relatively darker rim. Following treatment with Res (20, 30 and $40 \mu \mathrm{g} / \mathrm{ml}$ for $24 \mathrm{~h}$, or $35 \mu \mathrm{g} / \mathrm{ml}$ for 12,24 and $48 \mathrm{~h}$ ), the cell 

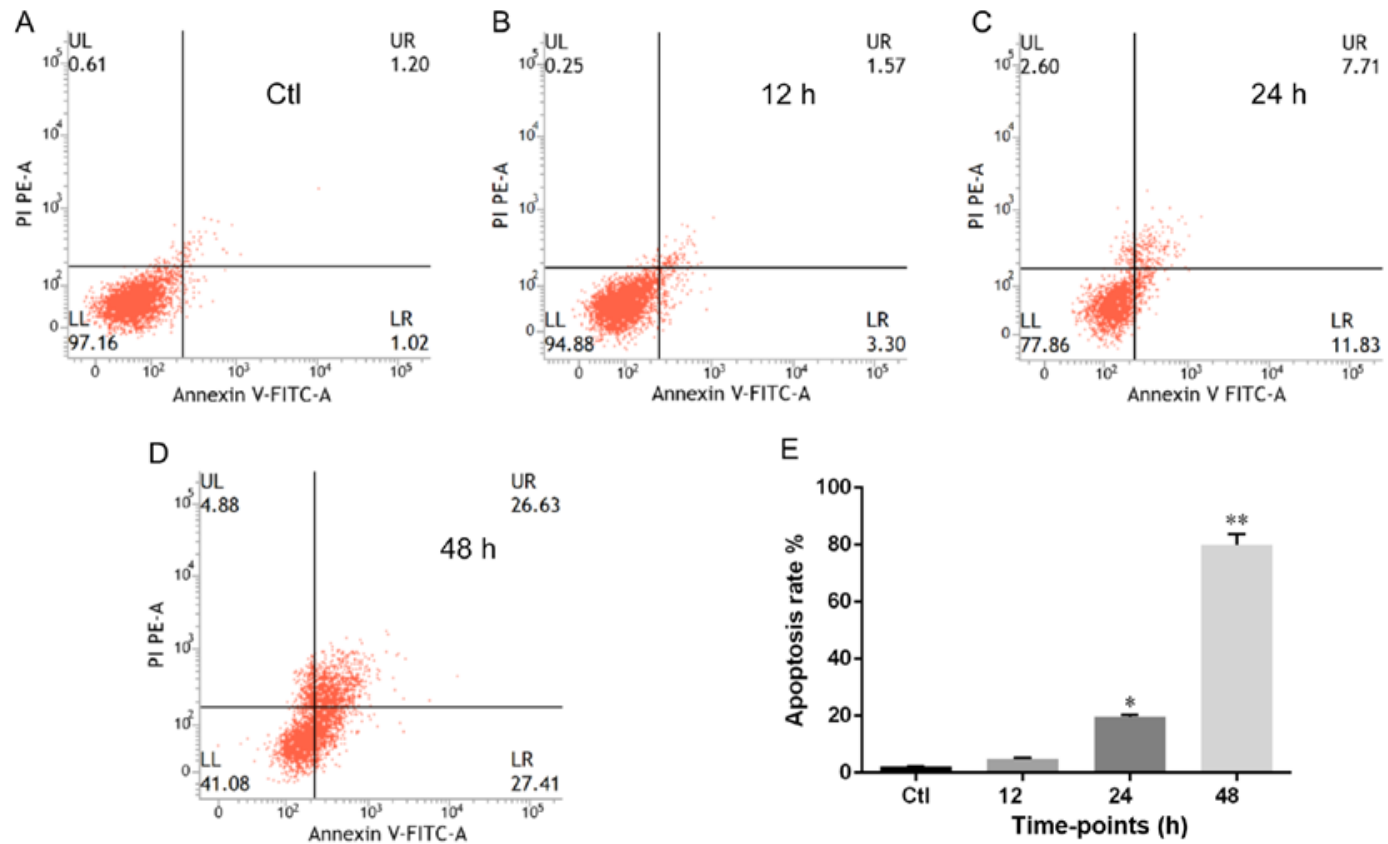

Figure 2. Resveratrol (Res) induces apoptosis in H446 cells as determined by flow cytometry. (A-D) Representative flow cytograms of H446 cells treated with $35 \mu \mathrm{g} / \mathrm{ml}$ Res for $0,12,24$ and $48 \mathrm{~h}$. (E) Apoptotic rates are expressed as mean \pm standard deviation. ${ }^{*} \mathrm{P}<0.05$ vs. control group; ${ }^{*} \mathrm{P}<0.05 \mathrm{vs}$. ${ }^{* *} \mathrm{P}$.
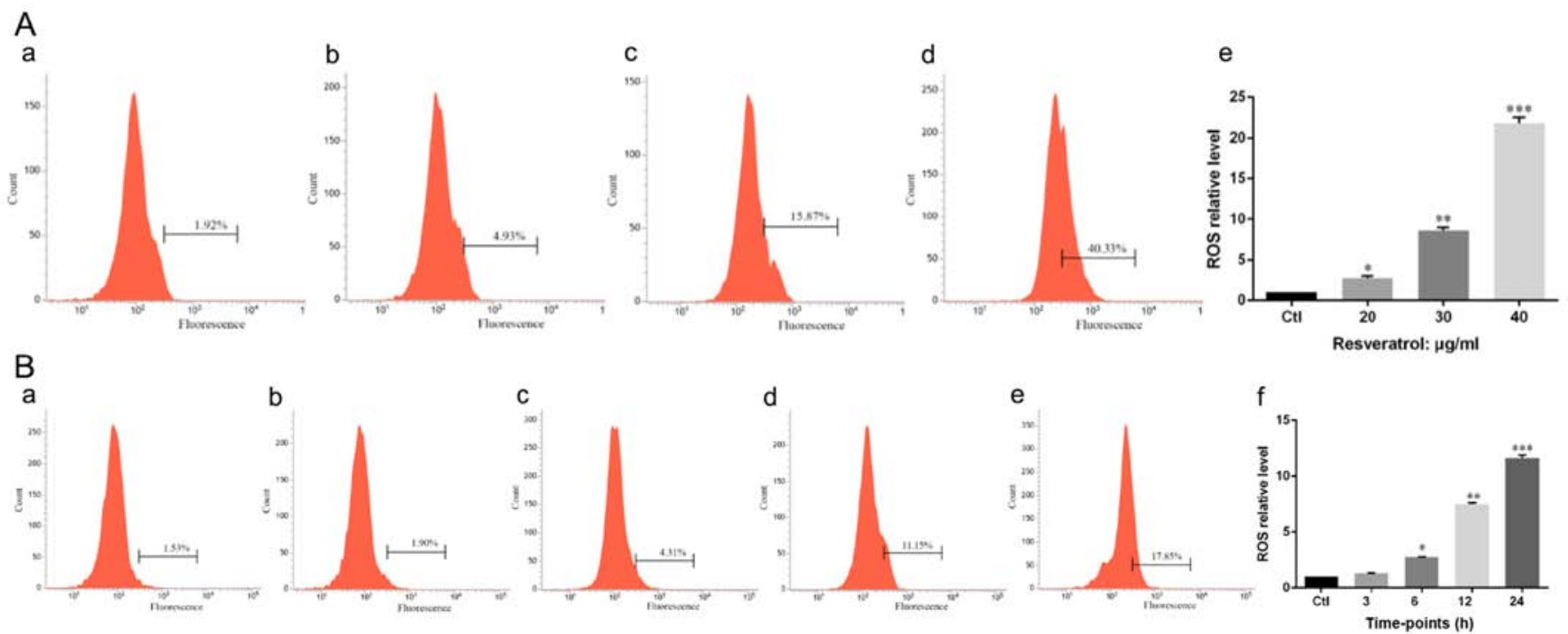

Figure 3. Effects of resveratrol (Res) on reactive oxygen species (ROS) generation in H446 cells. (A-a-d) Representative flow cytograms of H446 cells treated with 0,20,30 and $40 \mu \mathrm{g} / \mathrm{ml}$ Res for $24 \mathrm{~h}$. (B) ROS generation in $\mathrm{H} 446$ cells treated with $35 \mu \mathrm{g} / \mathrm{ml}$ Res for 0,3,6,12 or $24 \mathrm{~h}$. Data are presented as mean \pm standard deviation of three separate experiments (A-e and B-f). ${ }^{*} \mathrm{P}<0.05$ vs. control group; ${ }^{* *} \mathrm{P}<0.05$ vs. ${ }^{*} \mathrm{P} ;{ }^{* * *} \mathrm{P}<0.05$ vs. ${ }^{* *} \mathrm{P}$.

number was decreased to different extents, and the cells were not stretched as their control counterparts; in addition, different amounts of granular/refractory points were observed when the cells were treated with varied doses of Res, and the granular element increased in a dose-dependent manner.

Res stimulation promotes apoptosis of H446 cells. To further evaluate the anticancer properties of Res, H446 cells were treated with Res and apoptotic cells were detected as described above. The results (Fig. 2) demonstrated that Res treatment resulted in increased numbers of apoptotic $\mathrm{H} 446$ cells $(\mathrm{P}<0.05$ vs. control group). Of note, apoptotic cells were markedly increased after $48 \mathrm{~h}$ of incubation with Res compared with the 24-h group $(\mathrm{P}<0.05)$.

Res treatment results in enhanced ROS generation in $H 446$ cells. Res treatment resulted in increased intracellular ROS levels in H446 cells. Specifically, the results demonstrated increased ROS generation in $\mathrm{H} 446$ cells treated with $20 \mu \mathrm{g} / \mathrm{ml}$ Res for $24 \mathrm{~h}$ or $35 \mu \mathrm{g} / \mathrm{ml}$ Res for $6 \mathrm{~h}$ (both $\mathrm{P}<0.05$ vs. control group); furthermore, time- and dose-dependent increases in ROS levels were observed in cells treated with 30 and $40 \mu \mathrm{g} / \mathrm{ml}$ Res for $24 \mathrm{~h}$, or $35 \mu \mathrm{g} / \mathrm{ml}$ Res for 12 and $24 \mathrm{~h}$ (all $\mathrm{P}<0.05 \mathrm{vs}$. control cells) (Fig. 3). 

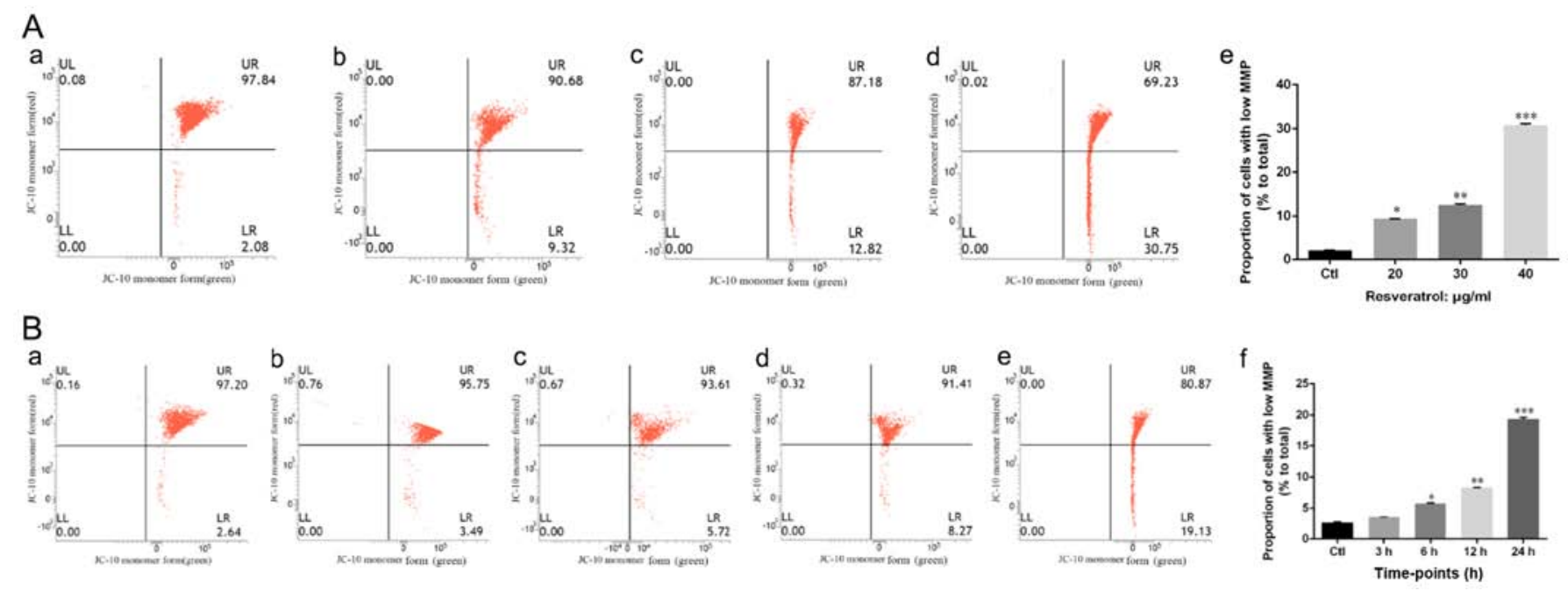

Figure 4. Mitochondrial membrane potential (MMP) in H446 cells treated with resveratrol (Res). MMP was assessed by JC-10 staining and measured by flow cytometry. (A) Numbers of H446 cells with reduced MMP following treatment with 0, 20,30 and $40 \mu \mathrm{g} / \mathrm{ml}$ Res for $24 \mathrm{~h}$; (A-a-d) representative flow cytometry diagrams. (B) Numbers of H446 cells with reduced MMP following treatment with $35 \mu \mathrm{g} / \mathrm{ml}$ Res for 0,3, 6, 12 or 24 h; (B-a-e) representative flow cytometry diagrams. Data are presented as the mean \pm standard deviation of three separate experiments $(\mathrm{A}-\mathrm{e}$ and $\mathrm{B}-\mathrm{f}) .{ }^{*} \mathrm{P}<0.05$ vs. control group; ${ }^{* *} \mathrm{P}<0.05$ vs. ${ }^{*} \mathrm{P} ;{ }^{* * *} \mathrm{P}<0.05$ vs. ${ }^{* *} \mathrm{P}$.

Res treatment results in decreased MMP in H446 cells. Based on the findings mentioned above, the MMP was further evaluated in cells treated with various concentrations of Res for $24 \mathrm{~h}$. While a few cells in the control group exhibited reduced MMP, significantly more cells with decreased MMP were found after treatment with $20 \mu \mathrm{g} / \mathrm{ml}$ Res ( $\mathrm{P}<0.05 \mathrm{vs}$. control group); in addition, the number of cells with reduced MMP increased with the Res dose $(\mathrm{P}<0.05$; Fig. 4A). Next, MMP changes were evaluated in $\mathrm{H} 446$ cells treated with $35 \mu \mathrm{g} / \mathrm{ml}$ Res at different times. The results demonstrated a significant decrease in MMP in H446 cells incubated with Res for $6 \mathrm{~h}$ $(\mathrm{P}<0.05$ vs. control group); an even higher number of cells with reduced MMP were detected after treatment with $30 \mu \mathrm{g} / \mathrm{ml}$ Res for 12 or $24 \mathrm{~h}$ (all $\mathrm{P}<0.05$; Fig. 4B).

Res treatment results in enhanced cytochrome c release and AIF translocation. To validate the critical function of mitochondria in Res-associated H446 cell apoptosis, cytochrome $c$ release from the mitochondrial compartment to the cytoplasm and AIF translocation were assessed in H446 cells. As shown in Fig. 5, Res treatment resulted in increased cytochrome $c$ content in the cytoplasm and AIF translocation from the mitochondria to the nucleus ( $\mathrm{P}<0.05$ vs. control group); in addition, a higher dose (30 or $40 \mu \mathrm{g} / \mathrm{ml})$ of Res or prolonged treatment (12 or $24 \mathrm{~h})$ markedly amplified these effects $(\mathrm{P}<0.05$ vs. control group).

Res regulates apoptotic factors. $\mathrm{Bcl}-2, \mathrm{Bcl}-\mathrm{xL}$ and $\mathrm{Bax}$ are well-known contributors to the intrinsic apoptotic pathway; therefore, the amounts of $\mathrm{Bcl}-2, \mathrm{Bcl}-\mathrm{xL}$ and $\mathrm{Bax}$ proteins in $\mathrm{H} 446$ cells were assessed by immunoblotting. As shown in Fig. 6, Res downregulated Bcl-2 and Bcl-xL expression ( $\mathrm{P}<0.05$ vs. control group), with higher doses $(30$ or $40 \mu \mathrm{g} / \mathrm{ml})$ or prolonged treatment (12 or $24 \mathrm{~h}$ ) exacerbating these effects (all $\mathrm{P}<0.05)$. Furthermore, treatment with Res resulted in higher Bax levels in $\mathrm{H} 446$ cells ( $\mathrm{P}<0.05$ vs. control group), in a time- and dose-dependent manner (all $\mathrm{P}<0.05$ ).
Res enhances the effects of cisplatin on cell growth. Based on the findings mentioned above, indicating that Res inhibits proliferation while inducing apoptosis in H446 cells by regulating the mitochondrial pathway, the effects of Res in augmenting the antitumor effects of cisplatin were further evaluated. As shown in Fig. 7A, cisplatin dose-dependently inhibited H446 cell growth. Furthermore, treatment with $35 \mu \mathrm{g} / \mathrm{ml}$ Res or $5 \mu \mathrm{g} / \mathrm{ml}$ cisplatin markedly reduced $\mathrm{H} 446$ cell proliferation ( $\mathrm{P}<0.05$ vs. control group), and combined treatment with the two agents resulted in an even more marked growth suppression in H446 cells in comparison with cisplatin or Res monotherapy (all $\mathrm{P}<0.05$; Fig. 7B).

Res treatment results in enhanced effects of cisplatin on ROS generation and mitochondrial depolarization. Next, we assessed how Res affects cisplatin-associated ROS production and MMP changes. As shown in Fig. 8, treatment with cisplatin $(5 \mu \mathrm{g} / \mathrm{ml})$ or Res $(35 \mu \mathrm{g} / \mathrm{ml})$ increased ROS generation, as well as the number of cells with decreased MMP (all $\mathrm{P}<0.05$ vs. control group). In addition, combining both agents at the abovementioned concentrations further enhanced ROS production in H446 cells, as well as the number of cells with reduced MMP, compared with the monotherapy groups (all $\mathrm{P}<0.05)$. These findings suggested that Res enhanced the effects of cisplatin on ROS generation and mitochondrial depolarization in $\mathrm{H} 446$ cells.

Res promotes cisplatin regulation of the mitochondrial apoptotic pathway. As shown above, Res enhanced the effects cisplatin on H446 cells, including growth inhibition, ROS production and mitochondrial depolarization. Therefore, we further investigated whether Res also alters the effects of cisplatin on the mitochondrial apoptotic pathway. As shown in Fig. 9A and B, treatment with cisplatin $(5 \mu \mathrm{g} / \mathrm{ml})$ resulted in increased cytochrome $c$ levels in the cytoplasm $(\mathrm{P}<0.05$ vs. control group) and increased AIF translocation $(\mathrm{P}<0.05$ vs. control group); furthermore, a markedly increased 
A
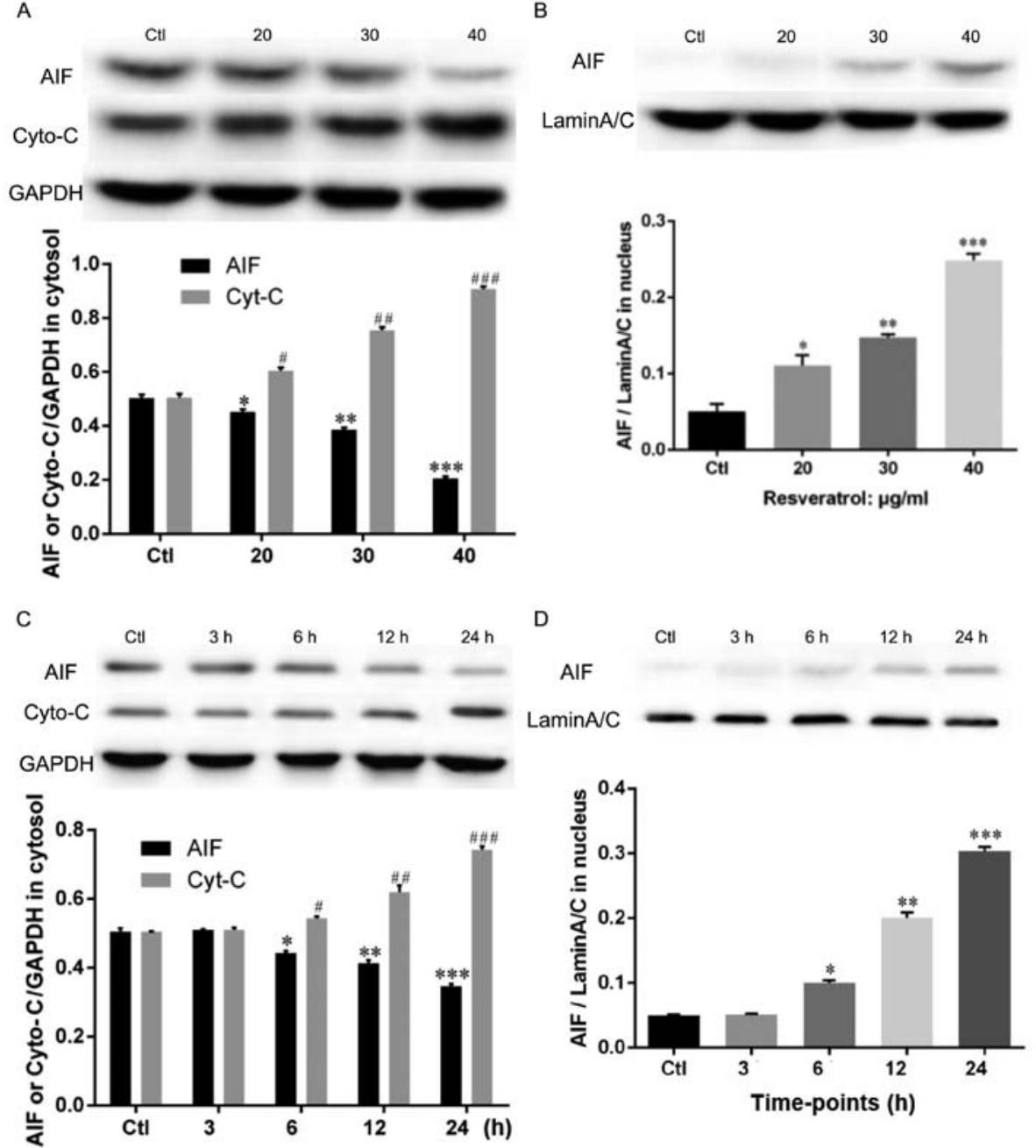

Figure 5. Cytochrome $c$ release from the mitochondria into the cytosol and AIF translocation from the mitochondria to the nucleus in $\mathrm{H} 446$ cells as detected by immunoblotting. (A and C) Treatment with 20,30 and $40 \mu \mathrm{g} / \mathrm{ml}$ resveratrol (Res) for $24 \mathrm{~h}$, or $35 \mu \mathrm{g} / \mathrm{ml}$ for 6,12 or $24 \mathrm{~h}$ markedly increased the Cyot-C content in the cytosol $\left({ }^{\#} \mathrm{P}<0.05\right.$ vs. control group; ${ }^{\# \#} \mathrm{P}<0.05$ vs. ${ }^{\#} \mathrm{P} ;{ }^{\# \# \#} \mathrm{P}<0.05$ vs. $\left.{ }^{\# \#} \mathrm{P}\right)$, while it decreased the content of AIF $\left(\right.$ P $<<0.05$ vs. control group; ${ }^{* * *} \mathrm{P}<0.05$ vs. ${ }^{*} \mathrm{P} ;{ }^{* * * *} \mathrm{P}<0.05$ vs. ${ }^{* *} \mathrm{P}$ ). (B and D) Furthermore, 20,30 and $40 \mu \mathrm{g} / \mathrm{ml}$ Res for $24 \mathrm{~h}$, or $35 \mu \mathrm{g} / \mathrm{ml}$ for 6,12 and $24 \mathrm{~h}$ significantly increased the content of AIF in the nucleus $\left({ }^{*} \mathrm{P}<0.05\right.$ vs. control group; ${ }^{* *} \mathrm{P}<0.05$ vs. ${ }^{3} \mathrm{P} ;{ }^{* * * *} \mathrm{P}<0.05$ vs. $\left.{ }^{* *} \mathrm{P}\right)$.

A

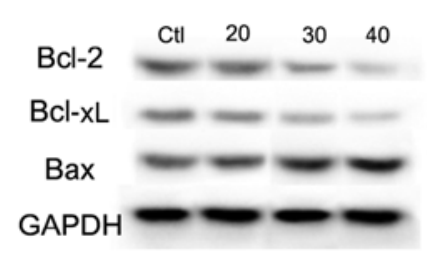

E

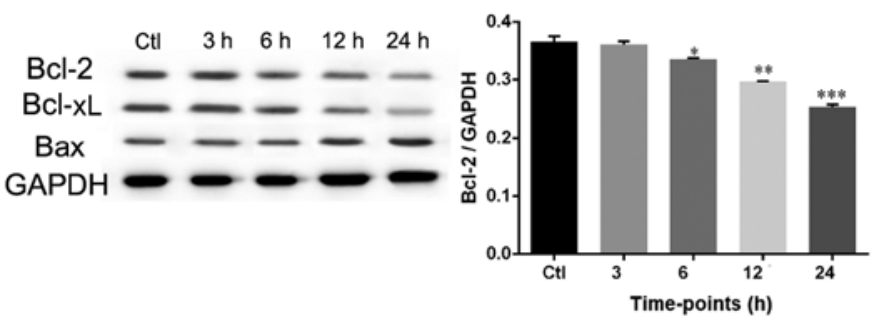

B

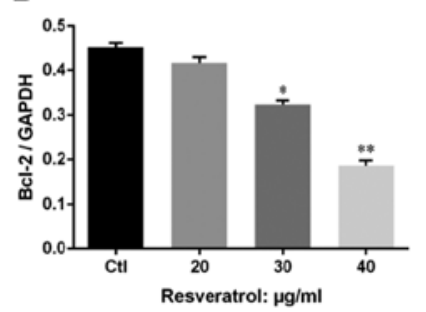

F

G
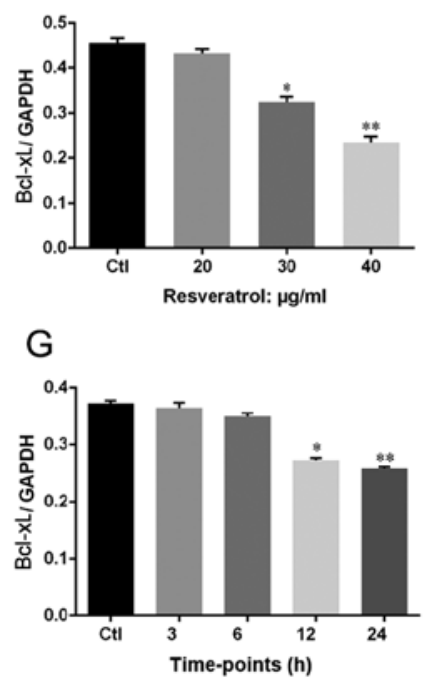

D

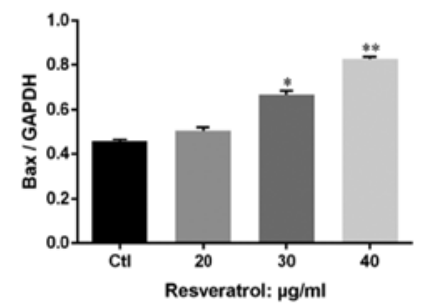

H

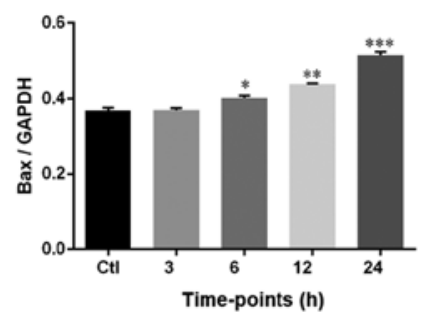

Figure 6. Expression levels of apoptosis regulators in $\mathrm{H} 446$ cells treated with resveratrol (Res). The expression levels of various proteins were evaluated by immunoblotting. (A-D) Bcl-2, Bcl-xL and Bax levels in H446 cells treated with 0, 20, 30 and $40 \mu \mathrm{g} / \mathrm{ml}$ Res for $24 \mathrm{~h}$. (E-H) Bcl-2, Bcl-xL and Bax levels in $\mathrm{H} 446$ cells treated with $35 \mu \mathrm{g} / \mathrm{ml}$ Res for $0,3,6,12$ or $24 \mathrm{~h}$. Data are presented as the mean \pm standard deviation of three separate experiments. ${ }^{*} \mathrm{P}<0.05 \mathrm{vs}$. control group; ${ }^{* *} \mathrm{P}<0.05$ vs. ${ }^{*} \mathrm{P} ;{ }^{* * *} \mathrm{P}<0.05$ vs. ${ }^{* *} \mathrm{P}$. 

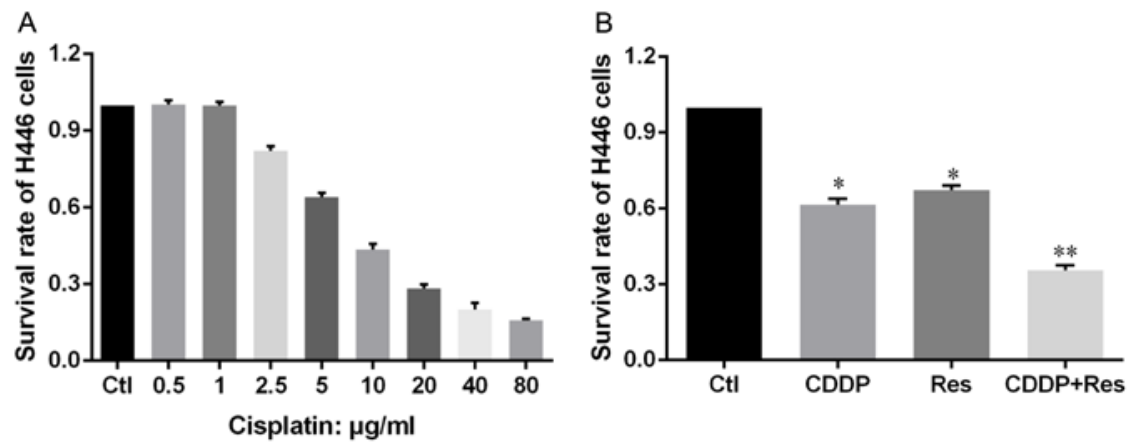

Figure 7. Combined treatment with cisplatin and resveratrol (Res) further inhibits $\mathrm{H} 446$ cell proliferation. Cell viability was measured by the MTT assay. (A) Cisplatin reduced $\mathrm{H} 446$ cell proliferation in a dose-dependent manner. (B) Res amplified the antitumor activity of cisplatin. ${ }^{*} \mathrm{P}<0.05$ vs. control; ${ }^{* * *} \mathrm{P}<0.05$ vs. ${ }^{*} \mathrm{P}$.
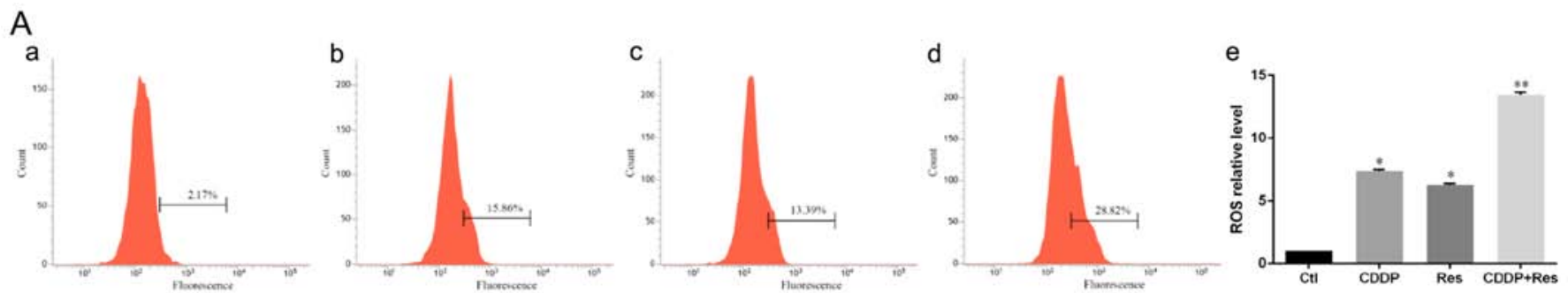

B
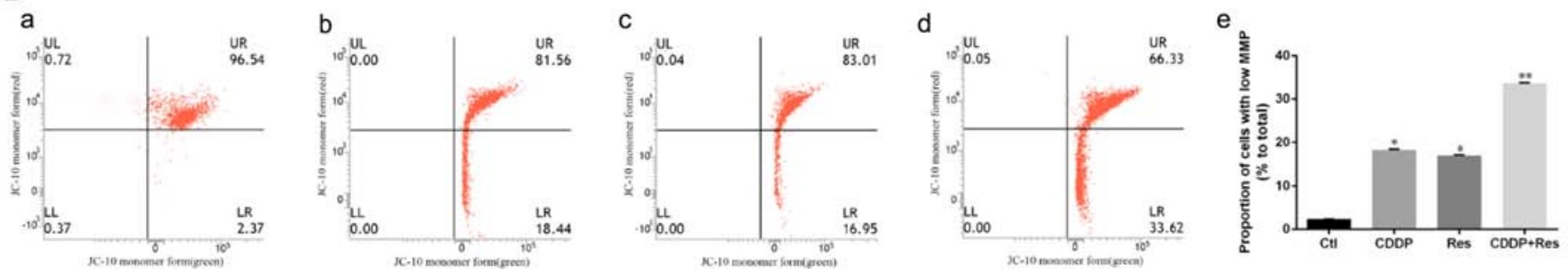

Figure 8. Resveratrol (Res) enhances the effects of cisplatin on reactive oxygen species (ROS) generation and mitochondrial depolarization. (A-a-d) Representative flow cytometry diagrams for ROS production levels in cells treated with cisplatin, Res, and cisplatin + Res. (B-a-d) Representative flow cytometry diagrams for mitochondrial membrane potential (MMP) in cells treated with cisplatin, Res, and cisplatin + Res. Quantification of (Ae) ROS and (Be) MMP; data are presented as the mean \pm standard deviation of three separate experiments. ${ }^{*} \mathrm{P}<0.05$ vs. control; ${ }^{* *} \mathrm{P}<0.05$ vs. ${ }^{*} \mathrm{P}$.

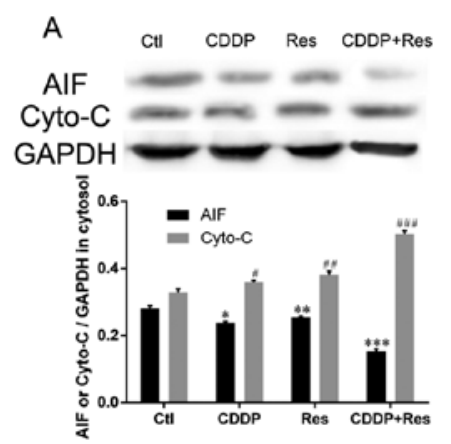

C

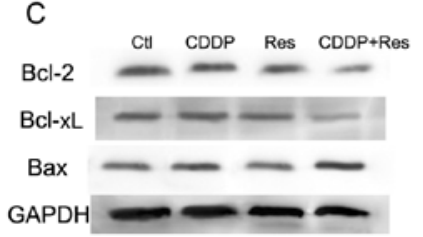

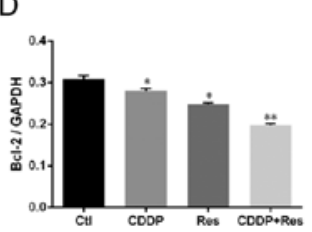

B AIF LaminA/C

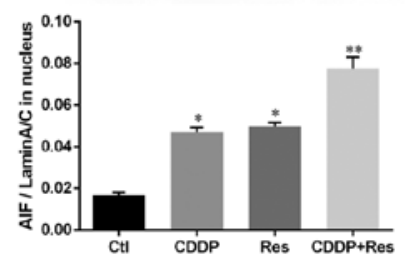

$\mathrm{E}$

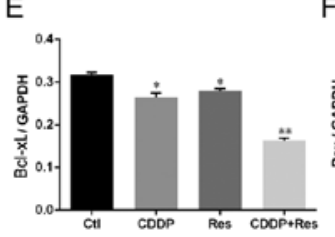

$\mathrm{F}$

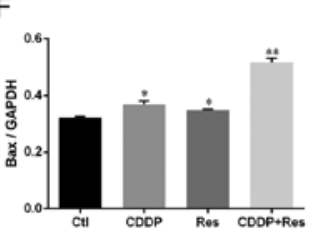

Figure 9. Resveratrol (Res) amplifies cisplatin-associated regulation of the mitochondrial apoptotic pathway and apoptosis regulators. Relative (A) apoptosisinducing factor (AIF) and Cyto-C expression levels in the cytosol, and (B) AIF levels in the nucleus of H446 cells treated with cisplatin, Res, and cisplatin + Res. Cyto-C release into the cytosol and AIF translocation from the mitochondria to the nucleus were increased in H446 cells treated with cisplatin; in addition, combined treatment with cisplatin and Res amplified these effects. " $\mathrm{P}<0.05$ vs. control; ${ }^{* *} \mathrm{P}<0.05$ vs. ${ }^{*} \mathrm{P}$. (C-F) Expression levels of Bcl-2, Bcl-xL and Bax in H446 cells treated with cisplatin, Res, and cisplatin + Res; data are presented as the mean \pm standard deviation of three separate experiments. "P $<0.05$ vs. control; ${ }^{* *} \mathrm{P}<0.05$ vs. ${ }^{*} \mathrm{P} ;{ }^{* * * *} \mathrm{P}<0.05$ vs. ${ }^{* *} \mathrm{P}$. 
cytochrome $c$ release and AIF translocation were observed after combined treatment with cisplatin and Res $(35 \mu \mathrm{g} / \mathrm{ml})$ (all $\mathrm{P}<0.05)$. Next, the levels of the Bcl-2, Bcl-xL and Bax proteins in $\mathrm{H} 446$ cells treated with cisplatin and/or Res were assessed by immunoblotting. As shown in Fig. 9C-F, treatment with Res or cisplatin downregulated Bcl-2 and Bcl-xL ( $\mathrm{P}<0.05$ vs. control group), while it upregulated Bax in H446 cells; these effects were further amplified in the combination group (all $\mathrm{P}<0.05)$.

\section{Discussion}

Cisplatin-based chemotherapy is effective as SCLC treatment, but it may also be intolerable to patients due to the side effects and development of drug resistance. Therefore, it is urgent to develop novel and efficient chemopreventive and chemotherapeutic drugs (19-21). Pharmacologically active ingredients from plants may be of great value for cancer patients, are they are generally associated with only moderate side effects. As one of such agents, Res exerts chemopreventive and chemotherapeutic effects in vitro and in vivo (13,22-24). Previous studies reported that Res enhances tumor cell sensitivity to chemotherapeutics (25), although the mechanism by which it sensitizes SCLC cells to cisplatin remains largely unknown. The aim of the present study was to evaluate the antitumor effects of Res on H446 cells and its impact on cisplatinassociated cancer inhibition.

As described above, Res concentration- and timedependently reduced cell proliferation, with morphological alterations also reflecting its pro-apoptotic properties in the SCLC H446 cell line. ROS is both the trigger and the further inducing factor in apoptosis, which is closely related to mitochondrial dysfunction. It is well known that ROS play a key role in modulating cell apoptosis, and chemotherapeutic strategies are often aimed at altering the oxidation and antioxidation balance by increasing ROS generation, leading to permanent damage that subsequently results in tumor cell apoptosis (26). In the process of cell apoptosis, uncoupling oxidative phosphorylation occurs in the respiratory chain, ROS production increases in the cells, and excessive ROS production leads to reduced MMP (27), whereas pro-apoptotic factors, including cytochrome $c$ and AIF, are released and trigger apoptosis $(28,29)$. Cytochrome $c$ release is closely regulated by the Bcl-2 family of proteins, which includes antiand pro-apoptotic entities (30-33). It is widely accepted that $\mathrm{Bcl}-2$ and $\mathrm{Bcl}-\mathrm{xL}$ act in preventing apoptosis and blocking cell death caused by various stressors $(34,35)$. By contrast, the Bax homodimer, which shares sequence homology with Bcl-2, is an important pro-apoptotic protein (36).

Previous studies have confirmed that high Res concentrations cause tumor regression, involving the mitochondrial intrinsic apoptotic pathway (37). In addition, it was suggested that Res-induced apoptosis may be mediated by Bcl-2 downregulation and Bax upregulation $(15,16,38)$. The present study also demonstrated that Res enhanced ROS production and mitochondrial depolarization in $\mathrm{H} 446$ cells; specifically, Res decreased Bcl-2 and Bcl-xL expression, increased Bax levels, enhanced cytochrome $c$ release and promoted mitochondrialnuclear translocation of AIF, which jointly resulted in apoptosis.
Next, the viability of $\mathrm{H} 446$ cells treated with cisplatin, Res, or cisplatin/Res combination was assessed, and the combination was found to be markedly more effective in inhibiting H446 cells compared with either monotherapy. In addition, combined treatment with cisplatin and Res induced apoptosis in H446 cells at a higher rate compared with either monotherapy. Furthermore, MMP reduction, increased cytochrome $c$ release and enhanced AIF translocation were all markedly amplified in the combination group compared with either monotherapy. Finally, combined treatment with cisplatin and Res resulted in sharper decrease of Bcl-2 and Bcl-xL levels and marked increase of Bax levels compared with the monotherapies.

In conclusion, the present study demonstrated that Res suppresses SCLC H446 cell growth and promotes apoptosis through the mitochondrial apoptotic pathway. Furthermore, Res may also enhance the antitumor effects of cisplatin, at least in part through the abovementioned mechanisms.

\section{Acknowledgements}

Not applicable.

\section{Funding}

This study was funded by the National Natural Science Foundation of China (grant no. 81071933).

\section{Ethics approval and consent to participate}

Not applicable.

\section{Patient consent for publication}

Not applicable.

\section{Availability of data and materials}

All analyzed data are available from the corresponding author on reasonable request.

\section{Authors' contributions}

WL and YS performed the experiments, which were designed and supervised by FJ and LM. RW and LP participated in data collection and analysis in this study.

\section{Competing interests}

The authors declare that they have no competing interests to disclose.

\section{References}

1. Lv C, Hong Y, Miao L, Li C, Xu G, Wei S, Wang B, Huang C and Jiao B: Wentilactone $\mathrm{A}$ as a novel potential antitumor agent induces apoptosis and G2/M arrest of human lung carcinoma cells, and is mediated by HRas-GTP accumulation to excessively activate the Ras/Raf/ERK/p53-p21 pathway. Cell Death Dis 4: e952, 2013.

2. Neal JW, Gubens MA and Wakelee HA: Current management of small cell lung cancer. Clin Chest Med 32: 853-863, 2011.

3. Mamdani H, Induru R and Jalal SI: Novel therapies in small cell lung cancer. Transl Lung Cancer Res 4: 533-544, 2015. 
4. Hsieh TC and Wu JM: Resveratrol: Biological and pharmaceutical properties as anticancer molecule. Biofactors 36: 360-369, 2010.

5. Kalantari $\mathrm{H}$ and Das DK: Physiological effects of resveratrol. Biofactors 36: 401-406, 2010.

6. Schnekenburger M, Dicato $M$ and Diederich M: Plant-derived epigenetic modulators for cancer treatment and prevention. Biotechnol Adv 32: 1123-1132, 2014.

7. Chan S, Kantham S, Rao VM, Palanivelu MK, Pham HL, Shaw PN, McGeary RP and Ross BP: Metal chelation, radical scavenging and inhibition of $A \beta_{42}$ fibrillation by food constituents in relation to Alzheimer's disease. Food Chem 199: 185-194, 2016.

8. Blanquer-Rosselló MD, Hernández-López R, Roca P, Oliver J and Valle A: Resveratrol induces mitochondrial respiration and apoptosis in SW620 colon cancer cells. Biochim Biophys Acta 1861: 431-440, 2017

9. Shakibaei M, Harikumar KB and Aggarwal BB: Resveratrol addiction: To die or not to die. Mol Nutr Food Res 53: 115-128, 2009.

10. Kundu JK and Surh YJ: Cancer chemopreventive and therapeutic potential of resveratrol: Mechanistic perspectives. Cancer Lett 269: 243-261, 2008.

11. Athar M, Back JH, Kopelovich L, Bickers DR and Kim AL: Multiple molecular targets of resveratrol: Anti-carcinogenic mechanisms. Arch Biochem Biophys 486: 95-102, 2009.

12. Goswami SK and Das DK: Resveratrol and chemoprevention. Cancer Lett 284: 1-6, 2009.

13. Delmas D, Lançon A, Colin D, Jannin B and Latruffe N: Resveratrol as a chemopreventive agent: A promising molecule for fighting cancer. Curr Drug Targets 7: 423-442, 2006.

14. Bhardwaj A, Sethi G, Vadhan-Raj S, Bueso-Ramos C, Takada Y, Gaur U, Nair AS, Shishodia S and Aggarwal BB: Resveratrol inhibits proliferation, induces apoptosis, and overcomes chemoresistance through down-regulation of STAT3 and nuclear factor-kappaB-regulated antiapoptotic and cell survival gene products in human multiple myeloma cells. Blood 109: 2293-2302, 2007.

15. Zhou HB, Chen JJ, Wang WX, Cai JT and Du Q: Anticancer activity of resveratrol on implanted human primary gastric carcinoma cells in nude mice. World J Gastroenterol 11: 280-284 2005.

16. Fuggetta MP, Lanzilli G, Tricarico M, Cottarelli A, Falchetti R, Ravagnan $\mathrm{G}$ and Bonmassar E: Effect of resveratrol on proliferation and telomerase activity of human colon cancer cells in vitro. J Exp Clin Cancer Res 25: 189-193, 2006.

17. Green DR, Galluzzi L and Kroemer G: Cell biology. Metabolic control of cell death. Science 345: 1250256, 2014.

18. Ma L, Li W, Wang R, Nan Y, Wang Q, Liu W and Jin F: Resveratrol enhanced anticancer effects of cisplatin on non-small cell lung cancer cell lines by inducing mitochondrial dysfunction and cell apoptosis. Int J Oncol 47: 1460-1468, 2015.

19. Aggarwal BB, Bhardwaj A, Aggarwal RS, Seeram NP, Shishodia $S$ and Takada Y: Role of resveratrol in prevention and therapy of cancer: Preclinical and clinical studies. Anticancer Res 24A: 2783-2840, 2004.

20. Donnelly LE, Newton R, Kennedy GE, Fenwick PS, Leung RH, Ito K, Russell RE and Barnes PJ: Anti-inflammatory effects of resveratrol in lung epithelial cells: Molecular mechanisms. Am J Physiol Lung Cell Mol Physiol 287: L774-L783, 2004.

21. Surh YJ: Cancer chemoprevention with dietary phytochemicals. Nat Rev Cancer 3: 768-780, 2003.

22. Jang M, Cai L, Udeani GO, Slowing KV, Thomas CF, Beecher CW, Fong HH, Farnsworth NR, Kinghorn AD, Mehta RG, et al: Cancer chemopreventive activity of resveratrol, a natural product derived from grapes. Science 275: 218-220, 1997.
23. Baur JA and Sinclair DA: Therapeutic potential of resveratrol: The in vivo evidence. Nat Rev Drug Discov 5: 493-506, 2006.

24. de la Lastra CA and Villegas I: Resveratrol as an antiinflammatory and anti-aging agent: Mechanisms and clinical implications. Mol Nutr Food Res 49: 405-430, 2005.

25. Frampton GA, Lazcano EA, Li H, Mohamad A and DeMorrow S: Resveratrol enhances the sensitivity of cholangiocarcinoma to chemotherapeutic agents. Lab Invest 90: 1325-1338, 2010.

26. Liou GY and Storz P: Reactive oxygen species in cancer. Free Radic Res 44: 479-496, 2010.

27. Zamzami N, Marchetti P, Castedo M, Decaudin D, Macho A, Hirsch T, Susin SA, Petit PX, Mignotte B and Kroemer G: Sequential reduction of mitochondrial transmembrane potential and generation of reactive oxygen species in early programmed cell death. J Exp Med 182: 367-377, 1995.

28. Polster BM and Fiskum G: Mitochondrial mechanisms of neural cell apoptosis. J Neurochem 90: 1281-1289, 2004.

29. Cregan SP, Dawson VL and Slack RS: Role of AIF in caspasedependent and caspase-independent cell death. Oncogene 23: 2785-2796, 2004.

30. Samarghandian S, Nezhad MA and Mohammadi G: Role of caspases, Bax and Bcl-2 in chrysin-induced apoptosis in the A549 human lung adenocarcinoma epithelial cells. Anticancer Agents Med Chem 14: 901-909, 2014.

31. Chen D, Zheng X, Kang D, Yan B, Liu X, Gao Y and Zhang K: Apoptosis and expression of the Bcl-2 family of proteins and P53 in human pancreatic ductal adenocarcinoma. Med Princ Pract 21: 68-73, 2012.

32. Chu SH, Lim JW, Kim DG, Lee ES, Kim KH and Kim H: Down-regulation of $\mathrm{Bcl}-2$ is mediated by NF- $\kappa \mathrm{B}$ activation in Helicobacter pylori-induced apoptosis of gastric epithelial cells Scand J Gastroenterol 46: 148-155, 2011.

33. Sun J, Li ZM, Hu ZY, Lin XB, Zhou NN, Xian LJ, Yang DJ and Jiang WQ: ApoG2 inhibits antiapoptotic Bcl-2 family proteins and induces mitochondria-dependent apoptosis in human lymphoma U937 cells. Anticancer Drugs 19: 967-974, 2008.

34. Kang CD, Jang JH, Kim KW, Lee HJ, Jeong CS, Kim CM, Kim SH and Chung BS: Activation of c-jun N-terminal kinase/ stress-activated protein kinase and the decreased ratio of Bcl-2 to Bax are associated with the auto-oxidized dopamine-induced apoptosis in PC12 cells. Neurosci Lett 256: 37-40, 1998.

35. Wang W, Guo Q, You Q, Zhang K, Yang Y, Yu J, Liu W, Zhao L, $\mathrm{Gu} \mathrm{H}, \mathrm{Hu} \mathrm{Y}$, et a: Involvement of bax/bcl-2 in wogonin-induced apoptosis of human hepatoma cell line SMMC-7721. Anticancer Drugs 17: 797-805, 2006.

36. Yang B, Johnson TS, Thomas GL, Watson PF, Wagner B, Furness PN and El Nahas AM: A shift in the Bax/Bcl-2 balance may activate caspase-3 and modulate apoptosis in experimental glomerulonephritis. Kidney Int 62: 1301-1313, 2002.

37. van Ginkel PR, Sareen D, Subramanian L, Walker Q, Darjatmoko SR, Lindstrom MJ, Kulkarni A, Albert DM and Polans AS: Resveratrol inhibits tumor growth of human neuroblastoma and mediates apoptosis by directly targeting mitochondria. Clin Cancer Res 13: 5162-5169, 2007.

38. Pozo-Guisado E, Merino JM, Mulero-Navarro S, LorenzoBenayasMJ, Centeno F, Alvarez-Barrientos A and Fernandez-Salguero PM: Resveratrol-induced apoptosis in MCF-7 human breast cancer cells involves a caspase-independent mechanism with downregulation of Bcl-2 and NF-kappaB. Int J Cancer 115: 74-84, 2005. 